\title{
THE EFFECTIVENESS OF GEOGEBRA WHEN TEACHING LINEAR FUNCTIONS USING THE IPAD
}

\author{
Vimolan Mudaly, Tamryn Fletcher \\ University of KwaZulu-Natal, South Africa \\ E-mail: mudalyv@ukzn.ac.za, tamfletch.1@gmail.com
}

\begin{abstract}
There is concern about mathematics success and its related pedagogy. Society has seen rapid changes in the economy and technology with a call for these changes to be reflected within the classroom. New methods of teaching mathematics are being sought with the purpose to improve teaching and learning while making mathematics relatable to the new generation of learners. The incorporation of technology within the classroom has been seen an option to make this change. The purpose of this research was to determine how effective the use of the GeoGebra app is in allowing learners to successfully discover the properties of straight line graphs. Furthermore, the research looked at learner responses to using the app. A qualitative research design was used with data generated through a task-based investigation, as well as individual interviews. Results of the research showed that the use of GeoGebra aided learners successfully in discovering the properties of straight-line graphs with the majority of learners understanding both concepts. The results also showed that learners had a positive outlook to the use of the app and enjoyed the experience.
\end{abstract}

Keywords: GeoGebra, iPad technology, mathematics teaching, linear functions, software manipulation.

\section{Introduction}

Rapid technological advancement is creating a fundamental change in most peoples' lives, especially influencing the way children learn. Anecdotal evidence is showing that learners are becoming highly skilled in technology (cell phones, IPad, Computers). Despite the existence of suitable technology that can be used in mathematics classrooms, learners are still expected to sit behind desks and listen to their teachers. Schools must therefore reform in order to accommodate these changes, adapting teaching methods to evolve with the technological revolution. Mathematics achievement within South Africa is poor and international tests (such as the TIMMS) show that we lie at the bottom of the table. As a result, alternative forms of teaching and learning have to be used to improve learners' conceptual understanding in mathematics.

The research focussed on the effectiveness of using technology in a Grade 9 mathematics classroom within a constructivist, collaborative pedagogical approach. Furthermore, the study looked at the reactions and perspectives of learners after working with the integrated technology. GeoGebra was used for this research. Interactions with practicing teachers indicated that technology is hardly used in South African schools because most schools do not have the infrastructure nor the financial capabilities for the purchase of such technology. There are other reasons for the absence of technology in the classroom, and these include amongst others, teachers' inability to use such technology and the lack of training in the incorporation of technology in mathematics lessons. 


\section{PROBLEMS \\ OF EDUCATION \\ IN THE $21^{\text {st }}$ CENTURY \\ Vol. 77 , No. 1, 2019 \\ 56}

Other researchers (Bester \& Brand, 2013; Stols et al, 2015; Padayachee, 2017) have researched the use of technology in South African classrooms and have concluded that the correct application of the technology results in a better understanding of concepts. In this research, the app version of GeoGebra was chosen because the majority of learners within schools possess smart phones or a mobile device that could be used to run the freely available GeoGebra app.

GeoGebra is an open source software, available to users for geometry and algebra. GeoGebra is easily downloadable into most computers or other technology that has a java enabled platform. In general, GeoGebra can be used for practically exploring concepts in geometry and algebra.

The purpose of this research was to determine whether the GeoGebra app could be used to get learners to successfully discover the properties of straight line graphs. This research was conducted in high school, based in the province of KwaZulu-Natal in South Africa. The school has approximately 1325 national and international learners. Digital learning is a relatively new and developing concept with the school's first initiative being introduced in 2014 with the introduction of IPad classes starting in grade nine. Since then, further upgrades in the online network have been seen together with the introduction of a learner system, namely Moodle, and a YouTube page.

The class used, comprised 27 mixed ability learners. Learners in this class were usually taught using a traditional approach where the teacher explained the content to the learners for half to three quarters of the lesson and the learner's role was to passively imbibe the information.

\section{Literature Review}

The intention of mathematics teaching and learning in South Africa, according to the Department of Basic Education (2011, p. 8), is to establish confident, proficient learners who have "deep conceptual understanding" of mathematics. In addition, the curriculum (Department of Basic Education, 2011, pp. 8-9), seeks to develop crucial mathematical skills within learners, including application skills, investigation skills, interpretation skills and problem solving skills to name just a few. Unfortunately, South African learners have shown substandard mathematics achievement clearly presenting a break down between the goals of the curriculum and its attainment (Spaull, 2014).

Conceptual and procedural knowledge and understanding are widely researched currently. Deep conceptual understanding can be described as the process which allows the person to form links with other concepts and to apply the concept in different contexts. A learner with conceptual understanding will know how to interpret and complete a question and more specifically, why they have used that particular method, naturally with an understanding of the interconnectedness of concepts. On the other hand, procedural knowledge and understanding is detailed by Rittle-Johnson and Alibali $(2009$, p. 175) as the "knowledge of action sequence for solving problems". Procedural knowledge is seen in learners when they demonstrate the sequence and rules to follow when completing a mathematical question. While the ultimate goal is to provide learners with the opportunity to have deep conceptual understanding, both forms of knowledge are important. Within the South African context, conceptual knowledge is tested in all formal assessment tasks based on the Curriculum and Assessment Policy Statement.

Mathematics has long been seen as a subject taught by the teacher to learners who often sit quietly and passively receive the knowledge being transferred (Morgado, 2010, p. 4; Swan, 2005, p. 3). This view is however changing and Zakaria, Solfitri, Daud, and Abidin (2013, p. 98) detail that in order for the understanding in mathematics to be strengthened, learners need to become active constructors of knowledge through the interaction with the teacher, their peers and the content. The reality is that learners struggle with mathematics and Murphy (2016, p. 
295) argued that the methods employed by teachers within the classroom will ultimately have consequences on a learner's level of understanding.

There was a focus on Functions in a grade nine mathematics class, and it was concentrated on the basic properties of straight-line graphs. This topic in mathematics is essential as it forms the basis for learning in the subsequent years. Within the South African curriculum, a large amount of time is dedicated to the teaching of Functions. Furthermore, the importance of Functions is ascertained by looking at the weighting of content areas in the end of year final exams written in schools in KwaZulu-Natal and set by the provincial Department of Basic Education as well as those set by individual schools. Approximately $30 \%$ of the first paper for grade ten and grade eleven contains questions related to Functions, with this figure increasing in the matric year. Anecdotal evidence shows that learners struggle with Functions and find concepts difficult to understand.

Birgin (2012, p. 141) described straight-line graphs as a multi-dimensional topic where conceptual understanding of the topic is essential for the success of learners. Birgin (2012) found that learners struggled with and had a very limited understanding of straight-line graphs as well as the concept of slope.

There is a global call for an improvement and modification in the way school mathematics is taught (Birgin, 2012, p. 140). It is widely known that we are in a digital era where technology has a large influence on society, and this has resulted in a change in the way education is viewed. Teachers and learners have greater access to technology, the internet and media. These can all be used for presenting lessons, enhancing understanding and for verifying results. Teachers need to reflect this change within their classrooms to align and meet the needs of the changing society and the needs of the learner. According to Zengin and Tatar (2017, p. 75) technology within the classroom is not a tool to transfer knowledge but rather a tool that provides the learner with an opportunity to engage and construct his or her own knowledge. An important concept, often misconstrued, is the fear that the introduction of technology within the classroom is used to replace the teacher but the incorporation of technology should rather be seen as a supporting tool that will aid learners in the visualization of concepts (Keskin, 2016, p. 2). Whilst technology supports teaching and learning in many ways, visualisation is an important concept which aids in successful teaching as it provides an opportunity for learners to visualise and engage with abstract concepts. Mathematics is a subject that requires a multifaceted approach and technology provides an opportunity for the teacher to teach maths in a variety of different ways. The software is convenient to use, and this provides an opportunity to create a multitude of different representations within the daily restrictive school time. Technology provides the opportunity to present a variety of representations and multiple opportunities to learn for the different learners, ensuring that many learners are provided for. These multiple representations can add depth to learners understanding of the concept which is important as we have seen that learners struggle with functions because there is often an emphasis on a procedural understanding rather than a conceptual one.

Recent years have seen numerous studies relating to technology in the classroom, with results showing the various benefits to teaching and learning. Bozkurt and Ruthven (2017, p. 317) found that "the accuracy and speed of GeoGebra facilitated the construction, modification, manipulation and measurement of figures by students". Similarly, Tatar and Zengin (2016), showed that dynamic software enabled retention and promoted conceptual understanding through visualization which ultimately improved the mathematics results. The study further found that the dynamic software aided in evolving the learners creative thinking skills by allowing them to manipulate the diagrams on the screen and simultaneously looking at the results presented. Supplementary to their previous study Zengin and Tatar (2017), found that dynamic software created a fun and delightful learning environment. With regards to learners and their interactions and responses to the dynamic software, Keskin's (2016) study 
Vimolan MUDALY, Tamryn FLETCHER. The effectiveness of Geogebra when teaching linear functions using the iPad

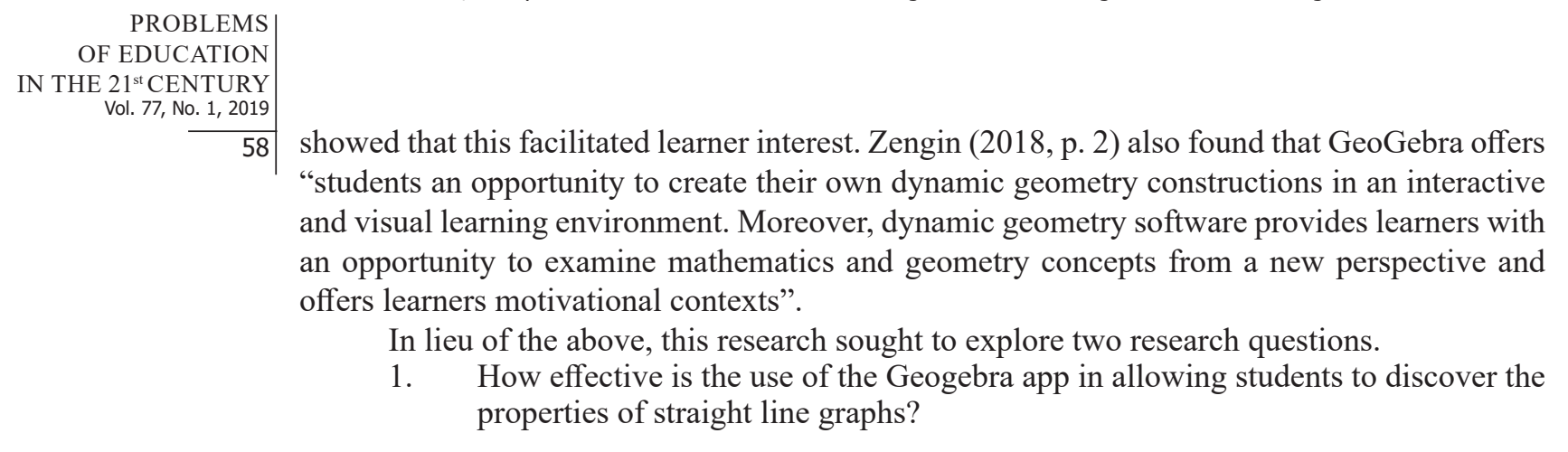

2. What were the students' views about using the app?

\section{Research Methodology}

\section{General Background}

In order to understand how effective GeoGebra was in enabling learners to discover the properties of straight-line graphs, namely gradient and y-intercept, the research sought learners' opinions and reactions about using the app. A qualitative research design was used. This type of design allows the researchers to attempt to derive a deeper understanding of the participants' actions, views and explanations through observations and interviews. The research was conducted in a grade 9 classroom in a public school in Pietermaritzburg, KwaZulu-Natal in South Africa, during the first quarter of the 2017 school term. The school is located in a medium to upper income social area, but learners choose to attend from lower income groups as well.

\section{Sample Selection}

The school had 4 classes of grade 9 learners but only two of them used IPads. A convenient, purposive sample was selected due to the involvement of a teacher from the school. So, one of the two grade nine IPad classes, containing 27 learners, was chosen as participants for the study based on convenience sampling, because this was the only class taught by one of the researchers and it was the only class where all students had an IPad.

Permission for the research was sought and granted. All ethical protocols were followed. Participants were assured that the results of their participation in the study would not influence their teacher's opinions nor their marks at school in any way.

\section{Conceptual Framework}

There are three important points to consider when using technology in mathematics classrooms (refer to Figure 1). What does the formal curriculum advocate? How easy is it to learn and use available and appropriate technology? How do learners perform in standardised tests and examinations?

Machnaik (2002, p. 7) claims that "working on computer-based projects, students became active learners collaborating with peers and teacher". She further drew from her own experience when she stated that "in my own teaching experience, I struggled with meeting the diverse needs of my students as we began integrating technology into different areas of study. Direct instruction was holding us back; a shift was needed. I began planning more independent, cooperative and project-based learning opportunities, allowing students to be active rather than passive learners" (Machnaik, 2002, p. 7)

Gilakjani, Sabouri and Zabihniaemran (2015, p. 213) also express the view that "the 
learning environment in a classroom can be changed by the computer technology. It is an important instrument for learning in the classroom and helps learners to succeed".

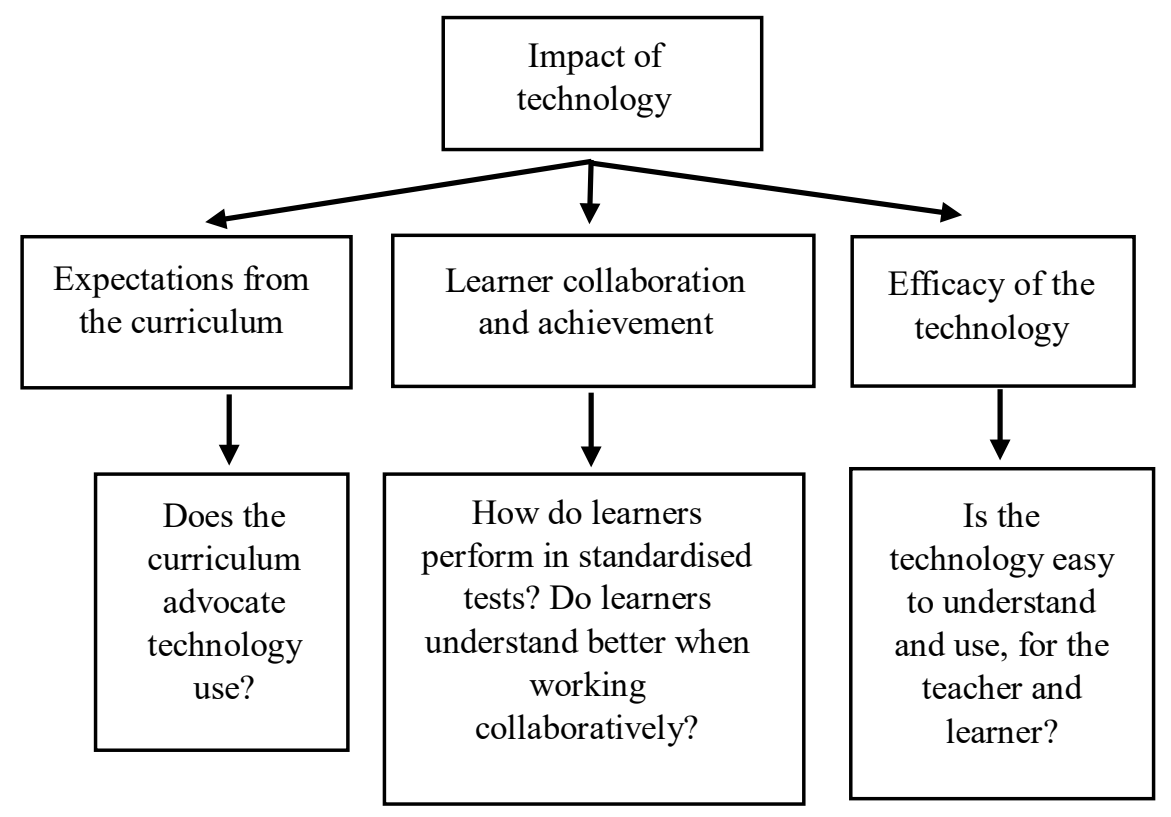

Figure 1. Conceptual framework.

\section{Instrument and Procedures}

The first part of the procedure allowed the participants to use the app to explore the different aspects of straight line graphs. Thereafter, they had to complete a task, without using the app, in order to assess their understanding of the concepts. The straight-line graph and its associated concepts were completely new to the participants. Prior to this research, their knowledge was limited to plotting points in the Cartesian plane.

Twenty-seven learners, in the class completed the exploration and task. The objectives of the exploration itself were that the learner would eventually be able to

- Describe the general equation of a straight-line graph.

- $\quad$ Read off the values of and when given the equation of a straight-line graph.

- Describe and its function in a straight-line graph.

- Describe and its function in a straight-line graph.

- Apply the properties of and in answering questions about straight-line graphs.

The straight line equation is represented in the general form $y=m \mathrm{x}+c$, where y represents the range (the values on the $y$ axis) and $x$ represents the domain (the values on the $x$-axis). The $m$ value is the gradient or slope and is the change in the $\mathrm{y}$-value divided by the change in the $\mathrm{x}$ value. The $c$ value is the y value at which the line cuts the $y$-axis. Refer to Figure 2 for a visual depiction. The $m$ value also represents an angle when written in the form $m=\tan \theta$. 
PROBLEMS

OF EDUCATION

IN THE $21^{\text {st }}$ CENTURY

Vol. 77, No. 1, 2019

60

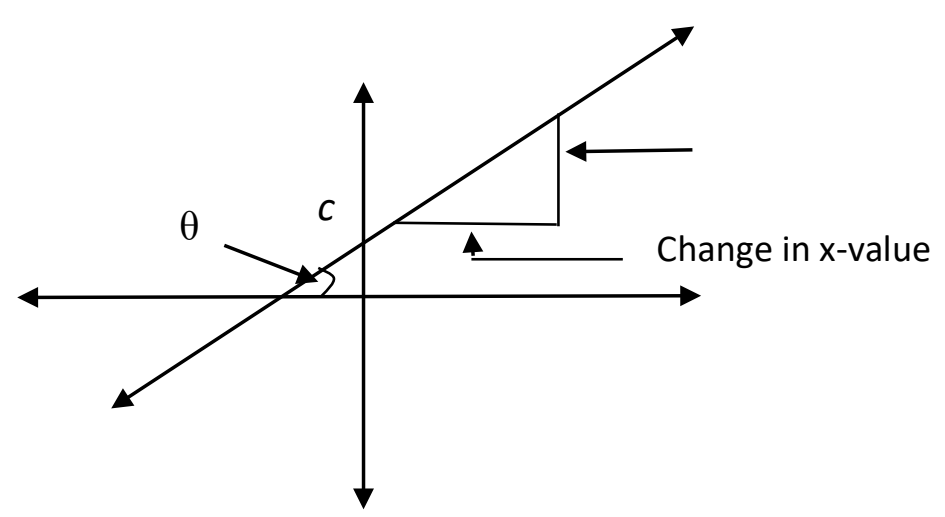

Figure 2. A visual representation of the straight line graph.

For the exploration, participants (in groups of four) were seated facing each other in order to allow for ease of communication and the creation of a collaborative learning environment. This ought to have encouraged learners to work together as a group where they could help each other with the content and concept. While learners were working together to complete the tasks, each learner used his/her own IPad to practically investigate and visualize the changes.

The app required for the investigation was downloaded by each participant from Moodle. The investigation had two parts where participants explored the function of first $m$ and then $c$ within the general equation of a straight-line graph. Participants first worked individually to manipulate the app using the sliders provided. Sliders are tools that are used to change variables without physically changing the values. This allows participants the opportunity to see instantaneously how the change in the slider affects the graph and provides the participants with a visual feedback which influenced their learning and understanding.

Two concepts were explored using the app. Participants changed the value of the $m$ and $c$ separately, recorded their findings on the investigation sheet, and developed generalisations about $m$ and $c$.

The task sheet was completed by the participants individually and was used to assess learners' understanding of the properties of linear functions using the GeoGebra app. The task was comprised of twelve questions.

Thereafter, five individual participants were selected randomly (the first five who volunteered) and interviewed. Standardized, open ended interviews were conducted with the intention of obtaining deep and insightful data (Cohen, Manion, \& Morrison, 2011, p. 411). Interviews provided an opportunity to move beyond the question of whether or not the app worked but allowed for the deeper examination of the learners' feelings about the use of the app. At the beginning of each interview learners were reassured of their anonymity and confidentiality. The interview questions were designed to obtain information firstly about the properties of the straight-line graphs and secondly to interrogate learners' opinions regarding their perceptions and challenges related to working with the app, investigations, task, group work in a collaborative setting and whether or not they would like more technology to be incorporated into lessons. 


\section{Research Results}

The data from the responses to the twelve questions in the task sheet were examined with a descriptive rubric, where each question was scored as either correct, moderately correct, incorrect or not answered. Questions that were in the standard form were answered easily. The participants did find some difficulty with the non-standard forms of the equation. This was expected because these types of questions did need some manipulation first.

Participants were correctly able to match the equation with its corresponding graph drawn in a table. The participants' knowledge of gradients was further reinforced when they correctly distinguished between lines with a positive, negative and zero gradients. Sixty seven percent of the participants were able to correctly distinguish between the three graphs.

Participants were able to identify how the shape of the straight line would change when the value of the gradient gets bigger or smaller. Seventy four percent of the participants provided correct responses. Eighty one percent of the participants identified the y-intercept given the equation. Participants were able to also distinguish between lines with a positive y-intercept from a line with a negative y-intercept. The participants' knowledge of the shape of the graph as the $y$-intercept changed was well answered with $93 \%$ of the participants obtaining the correct answer.

In the application questions participants were required to apply their knowledge of both gradient and straight line simultaneously. The results showed that the participants did better in the question where they had to draw a line with a positive gradient when compared to the question where the participants had to draw a line with a negative gradient. Results also showed that some participants struggled with the inequality signs and had the incorrect equation based on the question specification but could then draw the correct graph for the incorrect equation.

It is important to note that the participants had no pre-knowledge of straight-line graphs and had only seen a straight-line graph at the beginning of the investigation. As a result of the investigation and working with the app, all participants could read off $m$ and $c$ from an equation. They knew what $m$ and $c$ represented in the equation of a straight line, they could identify positive, negative and 0 gradients. They also knew what would happen when the $c$ value changed. Participants also showed that they could draw a sketch of the straight-line graph given particular information. It can be hypothesised that the app is effective for the successful discovery of the properties of straight-line graphs with the majority of learners being able to apply the concepts.

\section{Collaborative Learning Environment}

Analysing the participants' responses in the individual interviews provided useful qualitative data, which describes the participants' experiences and opinions of working with the app through a new teaching and learning method.

All five interviewed participants indicated that they enjoyed working with the app. Learners were further probed, by asking them what they enjoyed about working with the app with three of the five participants saying that the app makes learning interactive. They further elaborated by saying that this interaction allowed them the opportunity to do the work themselves which in turn made the work easier to understand. The responses by the other two learners saw them describing the experience as enjoyable because the app made doing the work simpler and was a different way of learning which made understanding easier. When participants were probed about challenges they encountered while working with the technology, there was a common response from participants. Initially, they struggled with working with the app. This could be a result of the learners adapting to the app as an innovation. They would have preferred to receive a 'crash course' on the basics of using the app. One participant described his experience when working with the app at first as a 'struggle'. He was initially confused because when he "touched a button and suddenly you have dots drawn all over the place". 


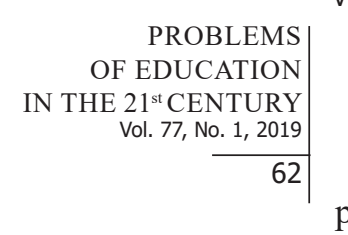

OROBLEMS

$21^{\text {st }}$ CENTURY

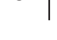

When participants were asked if they enjoyed doing the investigation and task, all five participants said that they did. When probed why, different responses were obtained which included the idea that it was fun as compared to their normal classwork and that this method helped them to understand the work better. When they asked if they encountered any challenges when working with the investigation and task, their responses included that there were no challenges.

Participants were asked about working in a group and whether or not they enjoyed the experience. Four of the participants said they enjoyed the experience. When one learner was asked why he did not enjoy the experience he explained that working in a group "is not everyone's forte". He further explained that he preferred being alone. When learners were asked if they thought working in a group helped in understanding the concept and completing the work, all of the participants felt that this did help because "you could get help from other group members if you did not understand something". One participant further explained that the group work helped if you were not sure and further elaborated that "sometimes it's better learning it from another learner than a teacher as you can understand it better".

Participants were asked if they enjoyed the innovative method of learning, namely working in a group in conjunction with the investigation while using the app. There were mixed reactions from the participants. Three of the five participants said they enjoyed this method of learning but showed hesitance by adding that this was a method they would need to get used to. When probed if this should be incorporated more into their class lessons, all of the participants agreed that it should with one participant stating that "you basically get to see what you are doing, and it is something you can refer to if you are not sure".

Lastly, participant responses were analysed based on the question of whether or not they think using the app was successful or not with all five participants saying the app was successful. A range of reasons were provided with one participant saying that it was "successful as it taught us in a different way". Another participant said that it was successful as it "allowed interactivity where you could see the lines physically move when you changed the values". Other reasons provided were, that it was successful because "it was a lesson we could actually understand", as well as the "app provided the opportunity for us to 'see' the change" and something to which they could refer.

The interviews reveal a positive outlook by participants towards the use of the GeoGebra app in a collaborative learning environment. Participants enjoyed working with the technology (app) and working in a group with participants, highlighting the benefits as being an interactive lesson, both with the app and with group members. Furthermore, participants felt that the work is easier to understand, with group members on hand to help those who may be struggling with the work. Participants showed in their interviews that they enjoyed this method of teaching, collaborative learning through group work, and suggested that this be incorporated more frequently into all mathematics lessons.

\section{Discussion}

Mathematics teaching and learning is often a complex activity. There must be a good relationship between the teacher, the learner, the activities and the artefacts used for teaching and learning. This research, whilst not producing new knowledge relating to the use of the iPad, it did show that teachers can creatively organise learning environments in order to use artefacts that learners are already familiar with.

The results showed that participants had a positive outlook towards investigations when working with the app. The participants revealed in the interviews that they enjoyed working with the app and this aligns with Zakaria et al's. (2013) and Zengin and Tatar's (2017) study which showed that technology created a positive and fun learning environment for 
participants. Even Hilton (2018, p. 145) obtained similar results when he stated that "survey results suggested that iPad use in mathematics has the potential to impact positively on students'attitudes to mathematics. The interview responses confirmed that iPads had a positive influence on students' engagement and attitudes to mathematics, and that the pedagogical approaches utilized by teachers for embedding iPads in their mathematics lessons contributed positively to these outcomes". The participants reported in their interviews that technology and, working in a group, created an interactive and engaging lesson and this finding aligns with the Tatar and Zengin (2016) study. Learners enjoyed working in their groups as this provided an opportunity for learners to help each other. Murphy's (2016) study shows that technology improved communication and interaction both between learners as well as between the learners and teacher and this outcome can be seen in this study where learners enjoyed working with other people and speaking and being helped by other group members. The participants, on more than one occasion in their interviews, stated that the technology made the work easier to understand. They elaborated further by saying that an added benefit of the app was the opportunity it provided for visualisation of the concept. This result aligns with Keskin (2016) and Tatar and Zengin (2016) findings which showed that dynamic software aided visualization which in turn helped learners with conceptual understanding.

Perhaps it is important to state that the iPad was not just used here for information gathering but rather for the purpose of creating understanding when dynamic software was used and manipulated by the learners themselves.

\section{Conclusions}

There were a number of significant findings from this research. In general, learners tend not to like mathematics. This is not just a South African phenomenon; it is true for mathematics learners throughout the world. These participants enjoyed working with the technology. Also, with the classroom innovation being different, it created enthusiasm amongst the learners. This is important for learners to understand mathematical concepts.

Secondly, the participants were happy to do the mathematics rather than be passive observers. This deviation from teacher centred strategies, allowed the learners to experience the mathematics themselves and this provided the ideal platform for them to learn concepts through trial and error.

Thirdly, most learners felt that they preferred to work in groups because it enabled them to consult with each other when in doubt or when they could not understand a particular concept. This type of group activity allowed for peer interaction and subsequent peer collaboration.

Finally, the learners engaged with the activities entirely on their own because the teacher simply served as a facilitator. At no point did the teacher intervene in the lesson itself, except for the provision of the task and the initial instructions. Although they could not successfully complete all the tasks, it is possible that had the teacher become more involved, through guidance, the learners might have experienced greater success with the app.

Looking at the results, it is evident that the app is successful in allowing participants to discover the properties of straight-line graphs. The participants moved from having no conceptualisation of the properties of straight-line graphs to being able to apply the knowledge in mixed application questions, all based on what they learnt during their explorations.

\section{References}

Bansilal, S. (2015). Exploring learner teachers' perceptions of the influence of technology in learning and teaching mathematics. South African Journal of Education, 35 (4), 01-08.

Bester, B., \& Brand, L. (2013). The effect of technology on learner attention and achievement in the classroom. South African Journal of Education, 33 (2), 1-15. 
Vimolan MUDALY, Tamryn FLETCHER. The effectiveness of Geogebra when teaching linear functions using the iPad

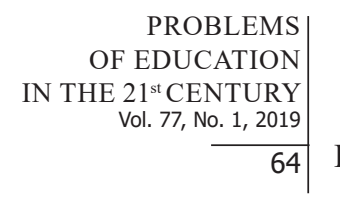

Birgin, O. (2012). Investigation of eighth-grade learners' understanding of the slope of the linear function. Bolema, 26 (42), 139-162.

Bozkurt, G., \& Ruthven, K. (2017). Classroom-based professional expertise: A mathematics teacher's practice with technology. Educational Studies in Mathematics, 94 (3), 309-328.

Capar, G., \& Tarim, K. (2015). Efficacy of the cooperative learning method on mathematics achievement and attitude: A meta-analysis research. Educational Sciences: Theory and Practice, 15 (2), 553559.

Cohen, L., Manion, L., \& Morrison, K. (2011). Research Methods in Education. London; New York: Routledge.

Department of Basic Education. (2011). National Curriculum Statement: Curriculum and Assessment Policy Statement (CAPS): Further Education and Training Phase: Grades 10-12 Mathematics. Retrieved from http://www.education.gov.za/Curriculum/CurriculumAssessmentPolicyStatement s(CAPS)/CAPSFET.aspx.

Gilakjani, A. P., Sabouri, N. B., \& Zabihniaemran, A. (2015). What are the barriers in the use of computer technology in EFL instruction? Review of European Studies, 7 (11), 213-221.

Hilton, A. (2018). Engaging primary school students in mathematics: Can iPads make a difference? International Journal of Science and Mathematics Education, 16 (1), 145-165.

Juhan, J. L., \& Halkias, D. (2017). Middle school mathematics teachers' experiences with student learning using the hands-on equations iPad application: A narrative inquiry. International Journal of Technology Enhanced Learning, 9 (1), 51-69.

Keskin, I. (2016). Evaluation of effectiveness of an enriched curriculum prepared using GeoGebra software. European Journal of Educational and Social Sciences, 1 (1), 1-10.

Machnaik, J. (2002). Investigating the effect(s) of technology integration on teaching practices that may lead to the development of a community of learners. Retrieved from http://www.usask.ca/ education/coursework/802papers//machnaik/machnaik.pdf.

Morgado, P. (2010). From passive to active learners: Implementing the pedagogy of "learning by doing" in a large-sized design foundation class. Transformative Dialogues: Teaching \& Learning Journal, $4(2), 1-12$.

Murphy, D. (2016). A literature review: The effect of implementing technology in a high school mathematics classroom. International Journal of Research in Education and Science, 2 (2), 295299.

Padayachee, K. (2017). A snapshot survey of ICT integration in South African schools. South African Computer Journal, 29 (2), 36-65.

Rittle-Johnson, B., \& Alibali, M. W. (1999). Conceptual and procedural knowledge of mathematics: Does one lead to the other? Journal of Educational Psychology, 91 (1), 175-189.

Spaull, N. (2014). Starting behind and staying behind: Insurmountable learning deficits in mathematics. Stellenbosch Economic Working Papers: 27/14. Retrieved from file://C:/Users/mudalyv/ Downloads/wp-27-2014\%20(2).pdf.

Stols, G., Ferreira, R., Pelser, A., Olivier, W. A., Van der Merwe, A., De Villiers, C., \& Venter, S. (2015). Perceptions and needs of South African mathematics teachers concerning their use of technology for instruction. South African Journal of Education, 35 (4), 1-13.

Swan, M. (2005). Improving learning in mathematics: challenges and strategies. Retrieved from https:// www.ncetm.org.uk/public/files/224/improving_learning_in_mathematicsi.pdf.

Tatar, E., \& Zengin, Y. (2016). Conceptual understanding of definite integral with GeoGebra. Computers in the Schools, 33 (2), 120-132.

Tsay, M., \& Brady, M. (2012). A case study of cooperative learning and communication pedagogy: Does working in teams make a difference? Journal of the Scholarship of Teaching and Learning, 10 (2), 78-89.

Zakaria, E., Solfitri, T., Daud, Y., \& Abidin, Z. Z. (2013). Effect of cooperative learning on secondary school learners' mathematics achievement. Creative Education, 4 (02), 98.

Zengin, Y. (2018). Incorporating the dynamic mathematics software GeoGebra into a history of mathematics course. International Journal of Mathematical Education in Science and Technology. Advance online publication. https://doi.org/10.1080/0020739X.2018.1431850.

Zengin, Y., \& Tatar, E. (2017). Integrating dynamic mathematics software into cooperative learning environments in mathematics. Journal of Educational Technology \& Society, 20 (2), 74-88. 


\section{Appendix 1}

Name:

Grade 9 Investigation: Properties of Straight line graphs

\section{Objectives of the Investigation and Task:}

1. Student is able to describe the general equation of a straight line graph.

2. Student is able to read off the values of and when given the equation of a straight line graph.

3. Student is able to describe what the property stands for and its function in a straight line graph.

4. Student is able to describe what the property stands for and its function in a straight line graph.

5. Student is able to apply the properties of and in answering questions about straight line graphs.

\section{The Straight line Graph}

The straight line graph is a linear graph which is formed by joining, with a ruler, two or more points together on the Cartesian plane.

Example of a straight line graph: is drawn below.

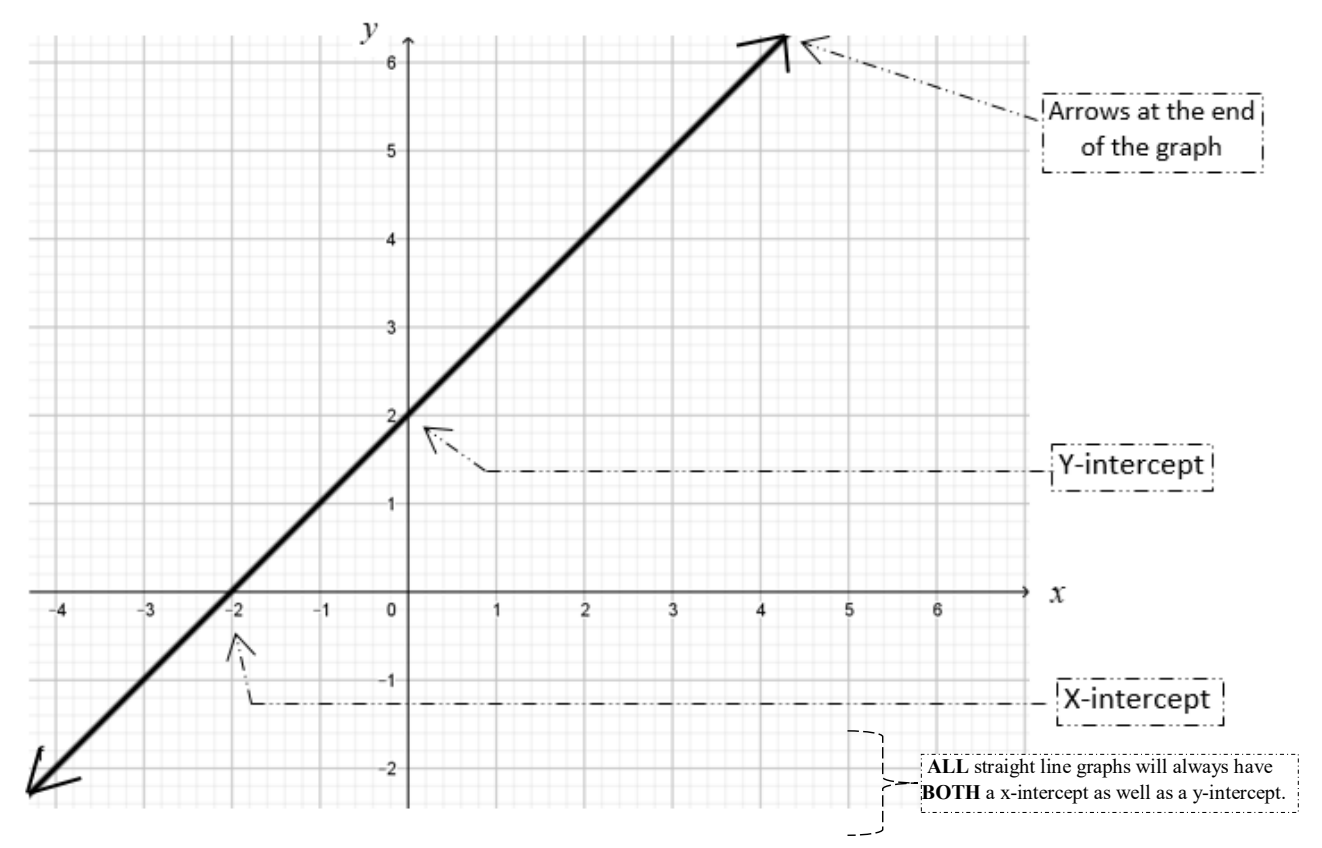

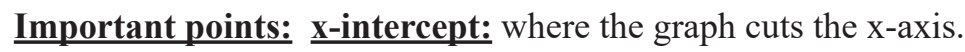

y-intercept: where the graph cuts the y-axis.

arrows: shows that the graph will keep on going to infinity in both directions

The general equation (formula) of a straight line graph is where and are values that are dependent on the straight line graph that is drawn. This general equation, (), is also called the standard form and when the equation is in this format, it allows the reader the opportunity to automatically read off the value for and. Examples are shown below: 


\begin{tabular}{|l|l|l|l|l|}
\hline Equation & $y=2 x-4$ & $y=-5 x+2$ & $y=\frac{x}{2}-5$ & $2 y=-4 x+10$ \\
\hline Value & $m=2 ; c=-4$ & $m=-5 ; c=2$ & $m=\frac{1}{2} ; c=-5$ & $m=-2 ; c=5$ \\
\hline
\end{tabular}

It is important to note that and each stand for a specific property within the equation and each have a specific function. You will now investigate each property independently with the use of the Geogebra App.

Open up the file, found on Moodle, called (Form 3 Investigation- properties of straight line graphs) on your Geogebra App. You are to follow the instructions (below) together with working on the App to answer the following questions. Write your answers in the space provided.

\section{Instructions Investigating $\mathrm{m}$}

a) Move the $\mathrm{m}$ slider (red one) to 1 and draw a rough sketch of the graph on the Cartesian plane provided below labelled Diagram A.

b) Move the $m$ slider to 2 and draw a rough sketch of the graph on Diagram A.

c) Move the $m$ slider to 3 and draw a rough sketch of the graph on Diagram A.

d) Move the $m$ slider to 4 and draw a rough sketch of the graph on Diagram A.

e)

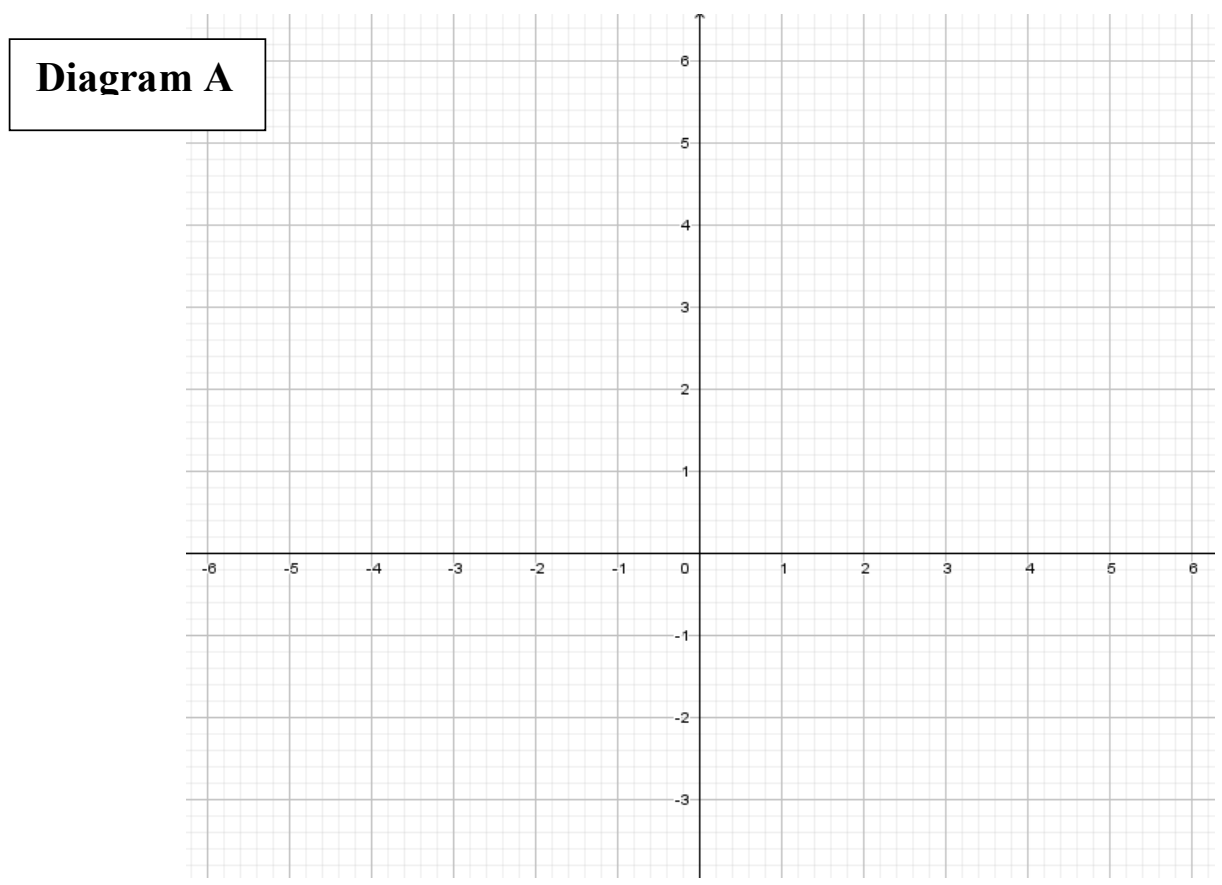




\section{Instructions}

1.1 What happens to the graph as the value of $m$ increases?

f) Move the m slider (red one) to -1 and draw a rough sketch of the graph on the Cartesian plane provided below labelled Diagram B.

g) Move the $m$ slider to -2 and draw a rough sketch of the graph on Diagram B.

h) Move the $m$ slider to -3 and draw a rough sketch of the graph on Diagram B.

i) Move the $m$ slider to -4 and draw a rough sketch of the graph on Diagram B.

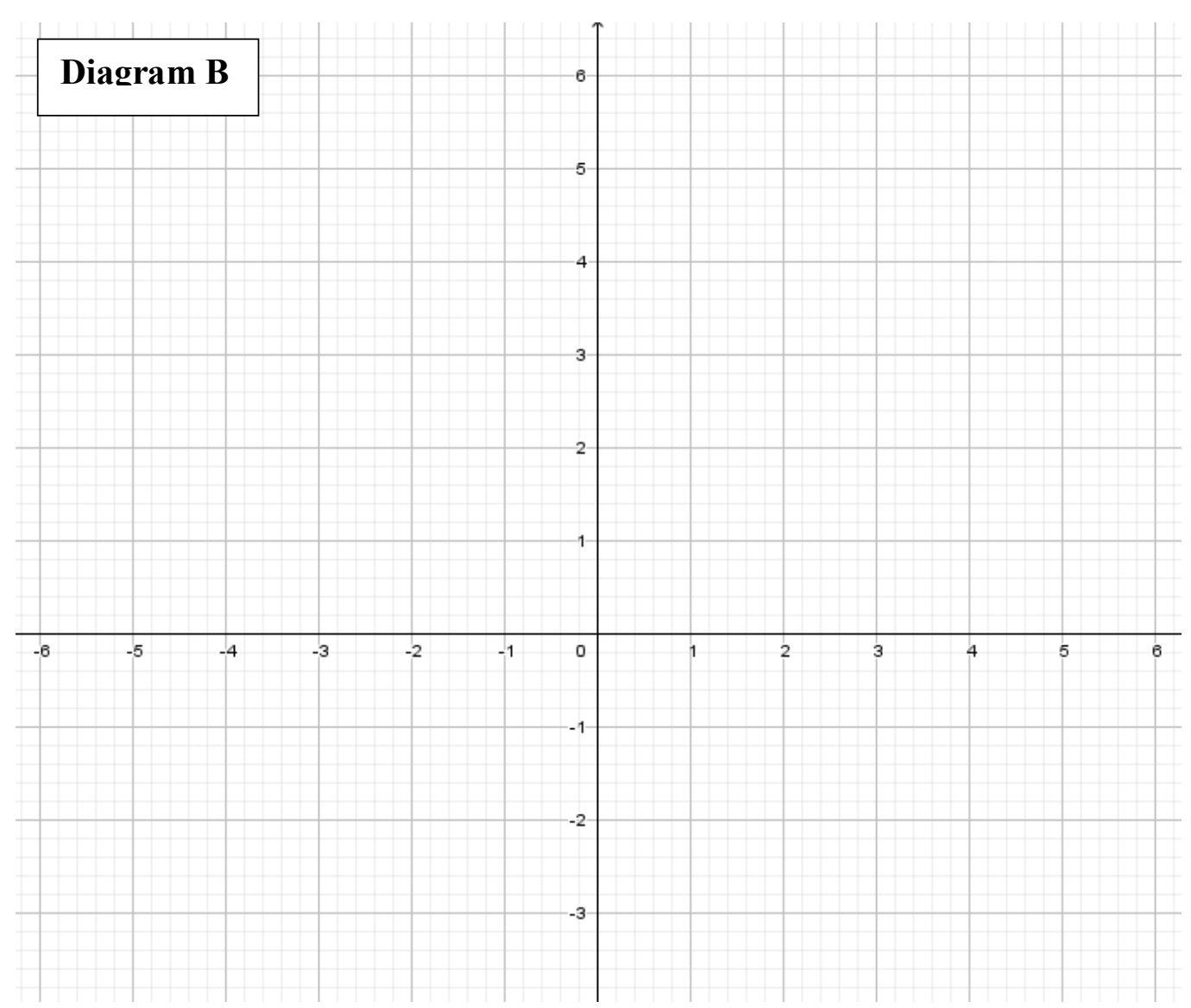


OF EDUC

IN THE $21^{\text {st }}$ CENTURY

Vol. 77 , No. 1,2019

\section{Ouestions}

1.1 What happens to the graph as the value of $\mathrm{m}$ becomes negative? How is this different to a positive $\mathrm{m}$ value?

1.2 What happens to the graph as the value of $\mathrm{m}$, being negative, gets smaller? i.e. $\mathrm{m}=$ $-1, \mathrm{~m}=-2$.

\section{Instructions}

a) Move the $m$ slider (red one) to 0. Draw a rough sketch of the graph on Diagram C.

b) Keep the $m$ slider at 0 and now change the $\mathrm{c}$ slider (blue one) to 1 and draw a rough sketch of the graph on Diagram C.

c) Again, keep the $\mathrm{m}$ slider at 0 and nw change the $\mathrm{c}$ slider to -1 and draw a rough sketch of the graph on Diagram C.

\section{Diagram C}

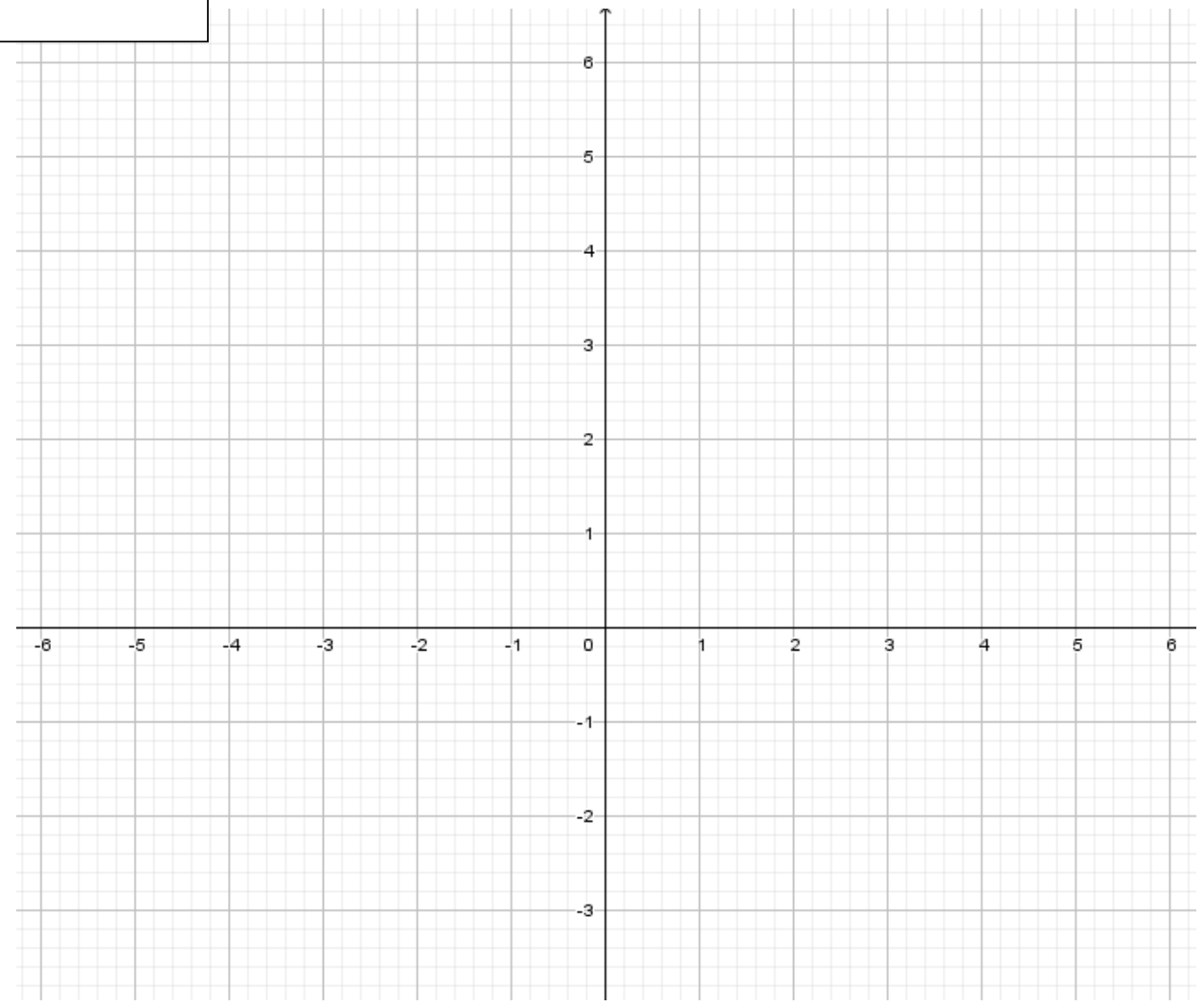




\section{Questions}

1.1 What happens to the graph when you changed $\mathrm{m}$ to 0 ?

\section{Conclusion:}

1. What do you think $m$ stands for in the equation of a straight line graph? (ie. name)

2. What happens when $m$ is positive compared to when $m$ is negative compared to when $\mathrm{m}$ is 0 ?

\section{Investigating $\mathbf{c}$}

a) Move the $\mathrm{m}$ slider (red one) to 1 and change the $\mathrm{c}$ slider (blue one) to 0 and draw a rough sketch of the graph on the Cartesian plane provided below labelled Diagram $\mathrm{D}$

a) Move the c slider to 1 and draw a rough sketch of the graph on Diagram D.

b) Move the c slider to 2 and draw a rough sketch of the graph on Diagram D.

c) Move the c slider to 3 and draw a rough sketch of the graph on Diagram D. 
PROBLEMS

OF EDUCATION

IN THE $21^{\text {st }}$ CENTURY

Vol. 77 , No. 1, 2019

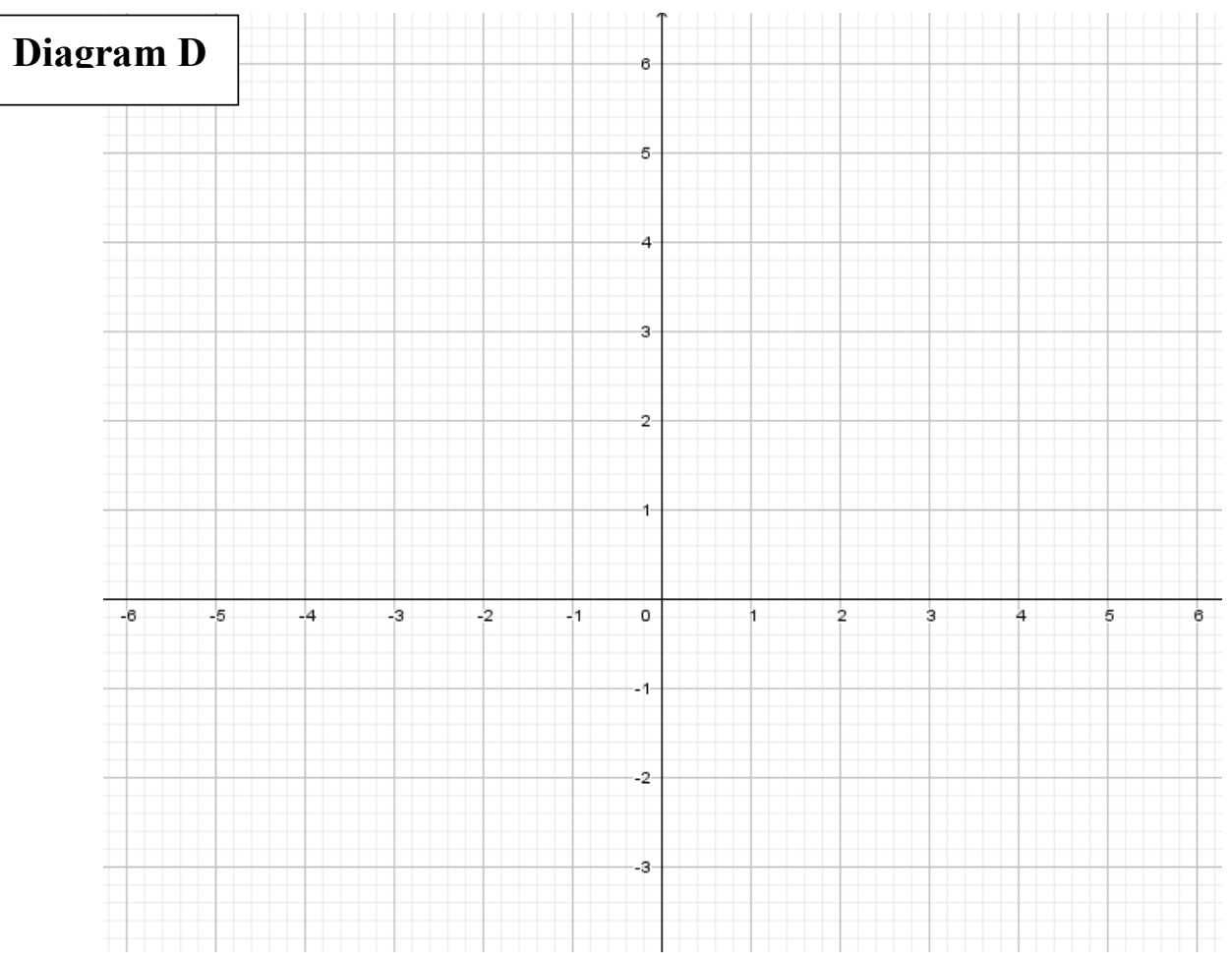

1.1 What happens to the graph as the value of $\mathrm{c}$ increases?

\section{Instructions}

d) Move the c slider (blue one) to 0 and draw a rough sketch of the graph on Diagram E.

e) Move the $\mathrm{c}$ slider to -1 and draw a rough sketch of the graph on Diagram $\mathrm{E}$.

f) Move the $\mathrm{c}$ slider to -2 and draw a rough sketch of the graph on Diagram $\mathrm{E}$. 
PROBLEMS

OF EDUCATION

IN THE $21^{\text {st }}$ CENTURY

Vol. 77, No. 1, 2019

71

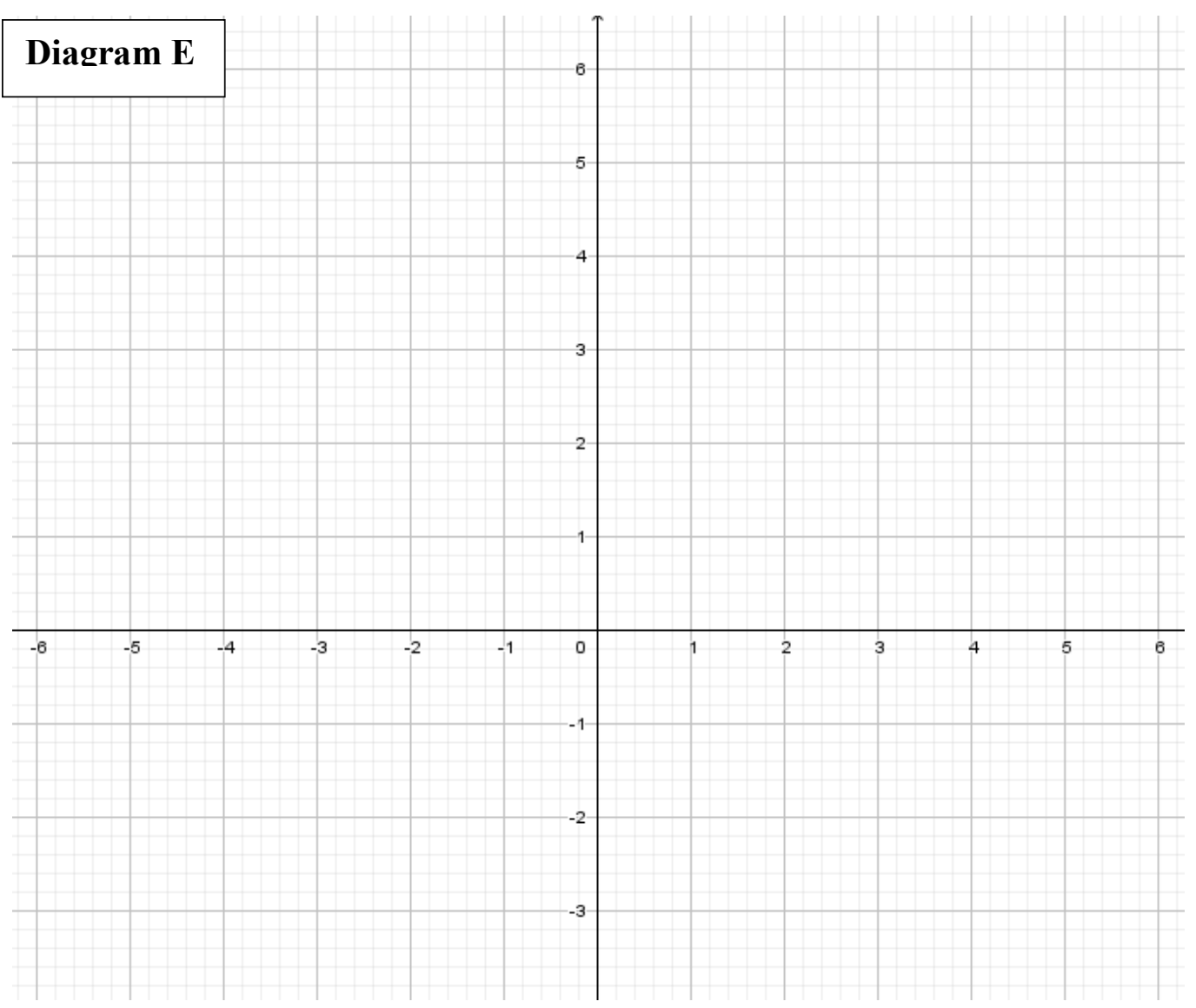

\section{Questions}

1.1 What happens to the graph as the value of $\mathrm{c}$ becomes negative?

\section{Conclusion:}

1. What do you think $\mathrm{c}$ stands for in the equation of a straight line graph? i.e. name 
Vimolan MUDALY, Tamryn FLETCHER. The effectiveness of Geogebra when teaching linear functions using the iPad

OF EDUCAT

PROBLEMS

THE $21^{\text {st }}$ CENTURY

Vol. 77, No. 1, 2019

2. What happens when $\mathrm{c}$ is positive compared to when $\mathrm{c}$ is negative compared to when $\mathrm{c}$ is 0 ?

Appendix 2

\section{Grade 9 Properties of Straight Line Graphs Task}

Name:

Class:

Mark:

1. Determine the value of and in the following straight line graphs:

1.1

1.2

1.3

1.4

1.5

$$
y=2 x+4
$$

$y=-x+8$

$y=3 x-2$

$$
y=x+2
$$

$$
2 y-4 x=-6
$$

(2)

(2)

)

(2)

$m$

(2)

$m=$

(2)

\begin{tabular}{|l|l|}
\hline$m=$ & $c=$ \\
\hline$m=$ & $c=$ \\
\hline$m=$ & $c=$ \\
\hline$m=$ & $c=$ \\
\hline$m=$ & $c=$ \\
\hline
\end{tabular}




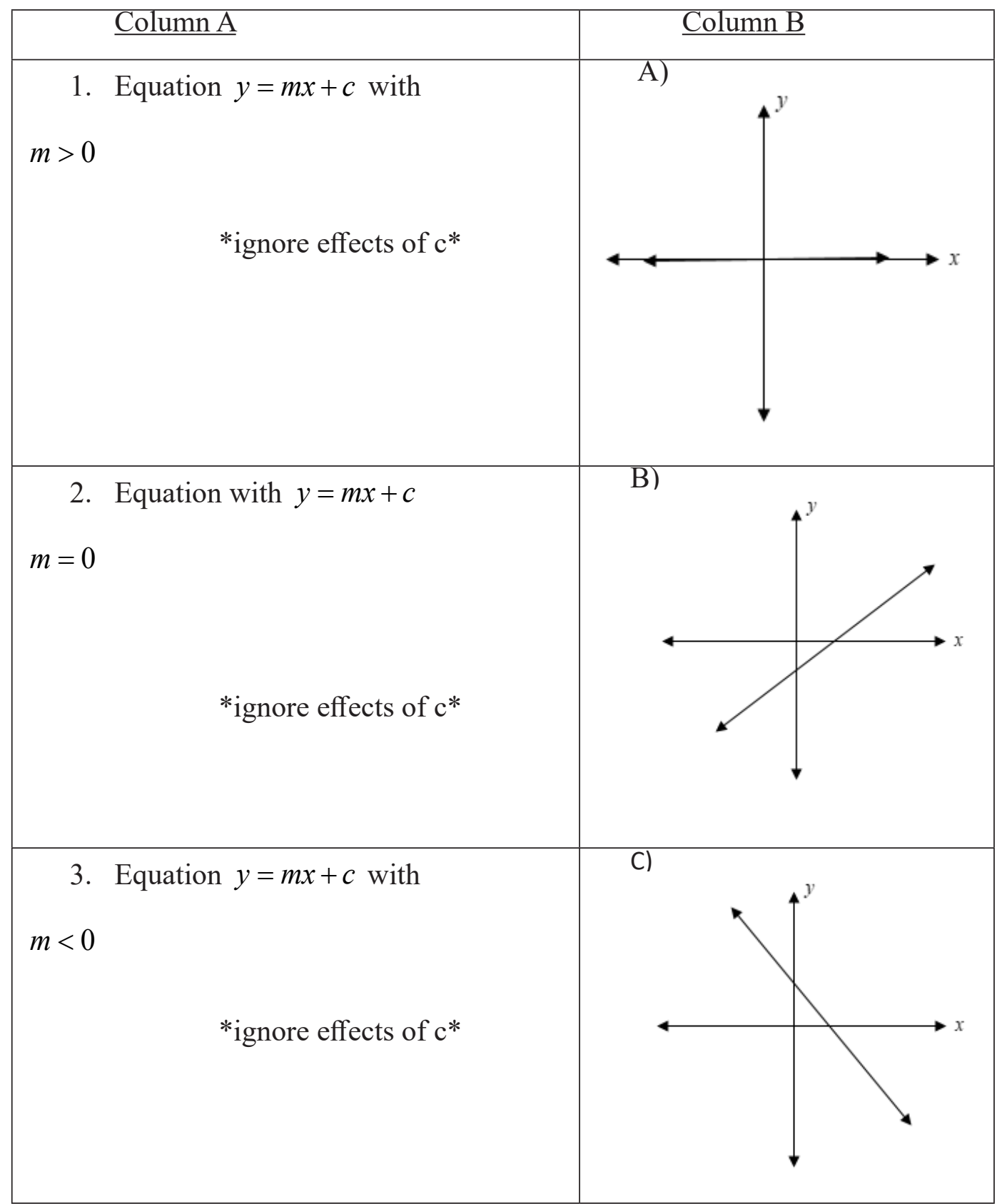

Vol. 77, No. 1, 2019 
Vimolan MUDALY, Tamryn FLETCHER. The effectiveness of Geogebra when teaching linear functions using the iPad

PROBLEMS

OF EDUCATION

IN THE $21^{\text {st }}$ CENTURY

Vol. 77, No. 1, 2019

Fill in your answer in the table below:

(Fill in A, B and C)

\begin{tabular}{|l|l|l|l|}
\hline Column A & 1 & 2 & 3 \\
\hline Column B & & & \\
\hline
\end{tabular}

(3)

5. Match the properties described in Column A with the correct (corresponding) graph in Column B.

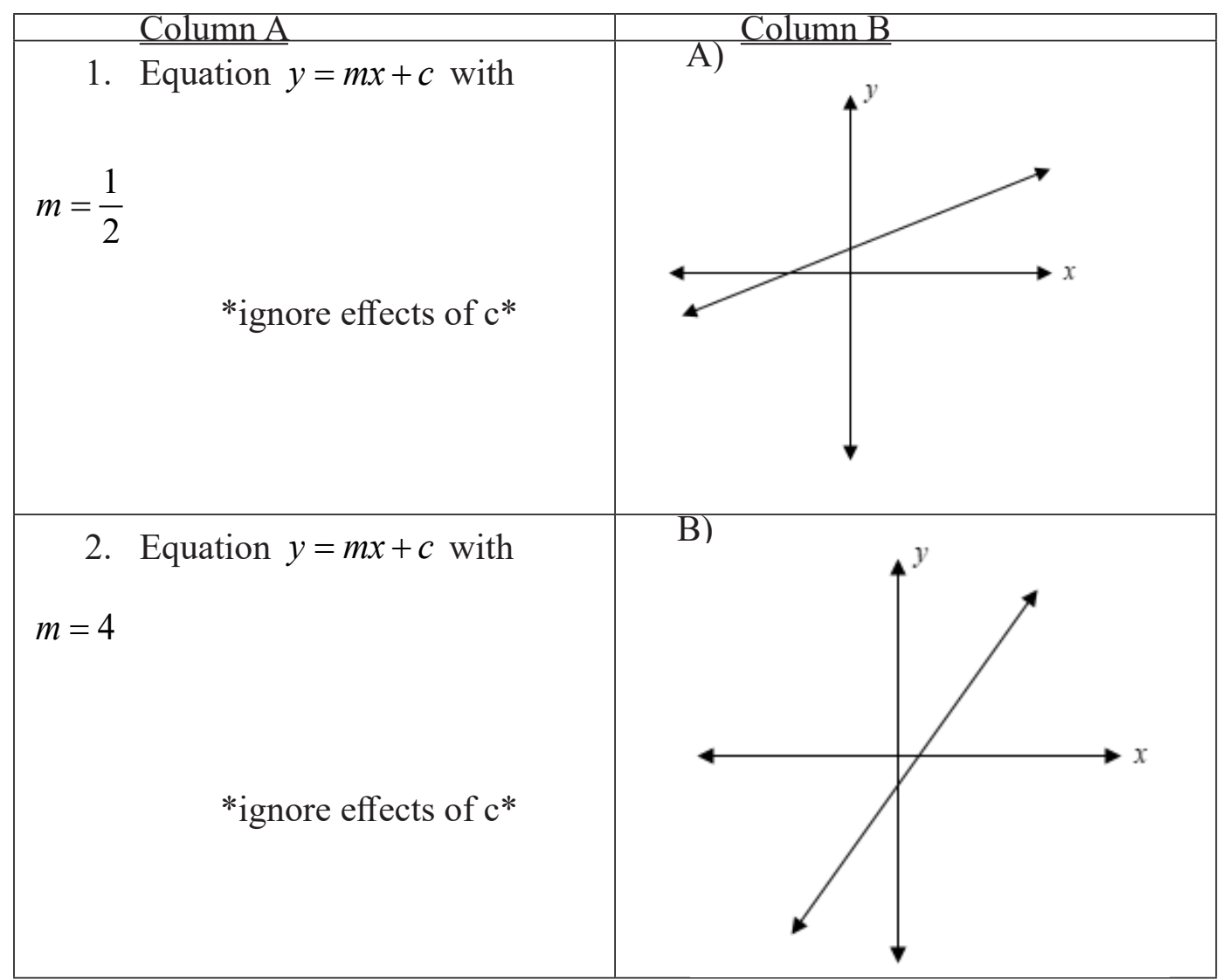

Fill in your answer in the table below:

(Fill in A and B) 


\begin{tabular}{|l|l|l|}
\hline Column A & 1 & 2 \\
\hline Column B & & \\
\hline
\end{tabular}

(2)

6. Match the properties described in Column A with the correct (corresponding) graph in Column B.

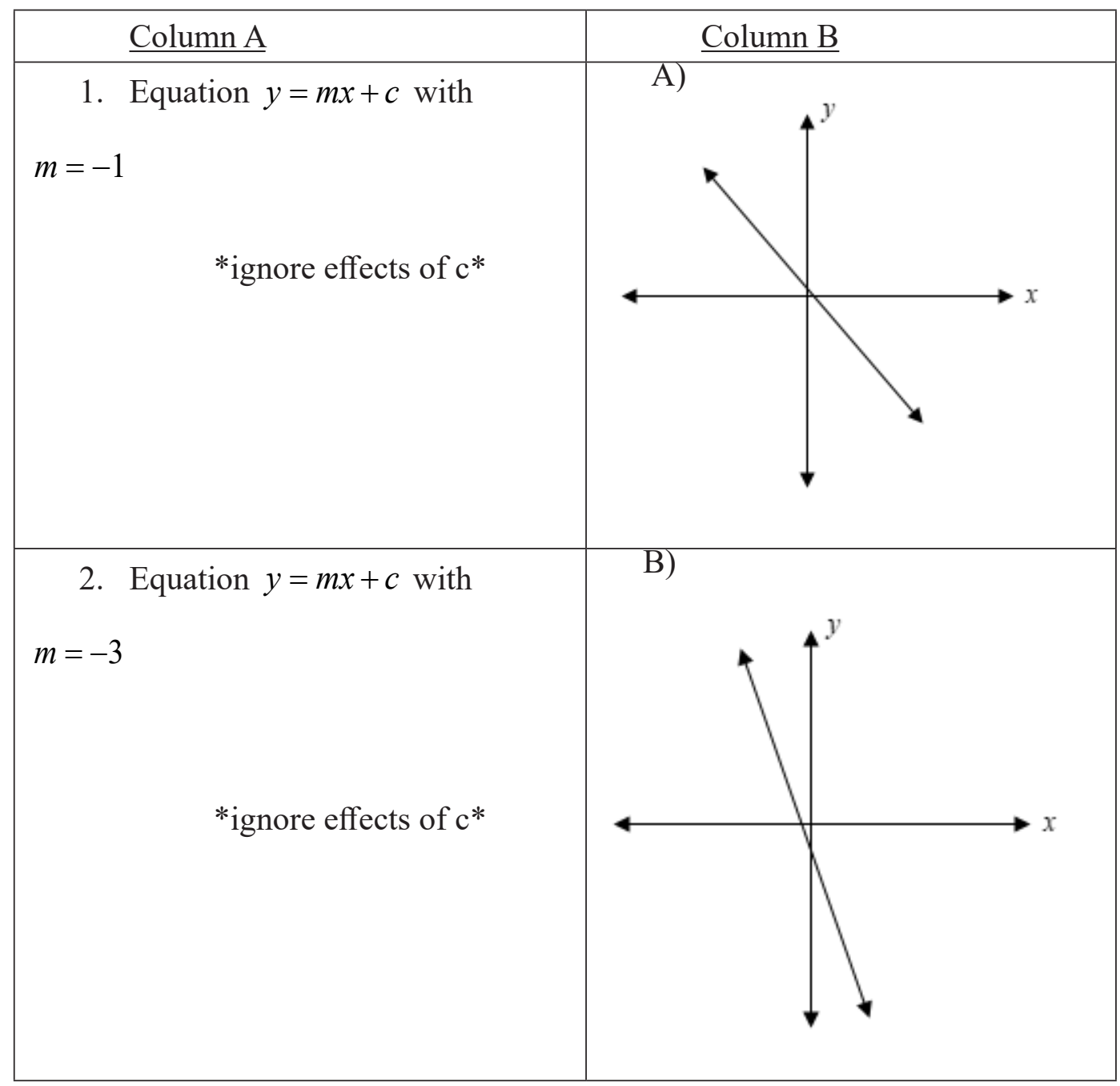

Fill in your answer in the table below:

(Fill in A and B) 
Vimolan MUDALY, Tamryn FLETCHER. The effectiveness of Geogebra when teaching linear functions using the iPad

PROBLEMS

OF EDUCATION

IN THE $21^{\text {st }}$ CENTURY

Vol. 77, No. 1, 2019

\begin{tabular}{|l|l|l|}
\hline Column A & 1 & 2 \\
\hline Column B & & \\
\hline
\end{tabular}

(2)

7. Match the properties described in Column A with the correct (corresponding) graph in Column B.

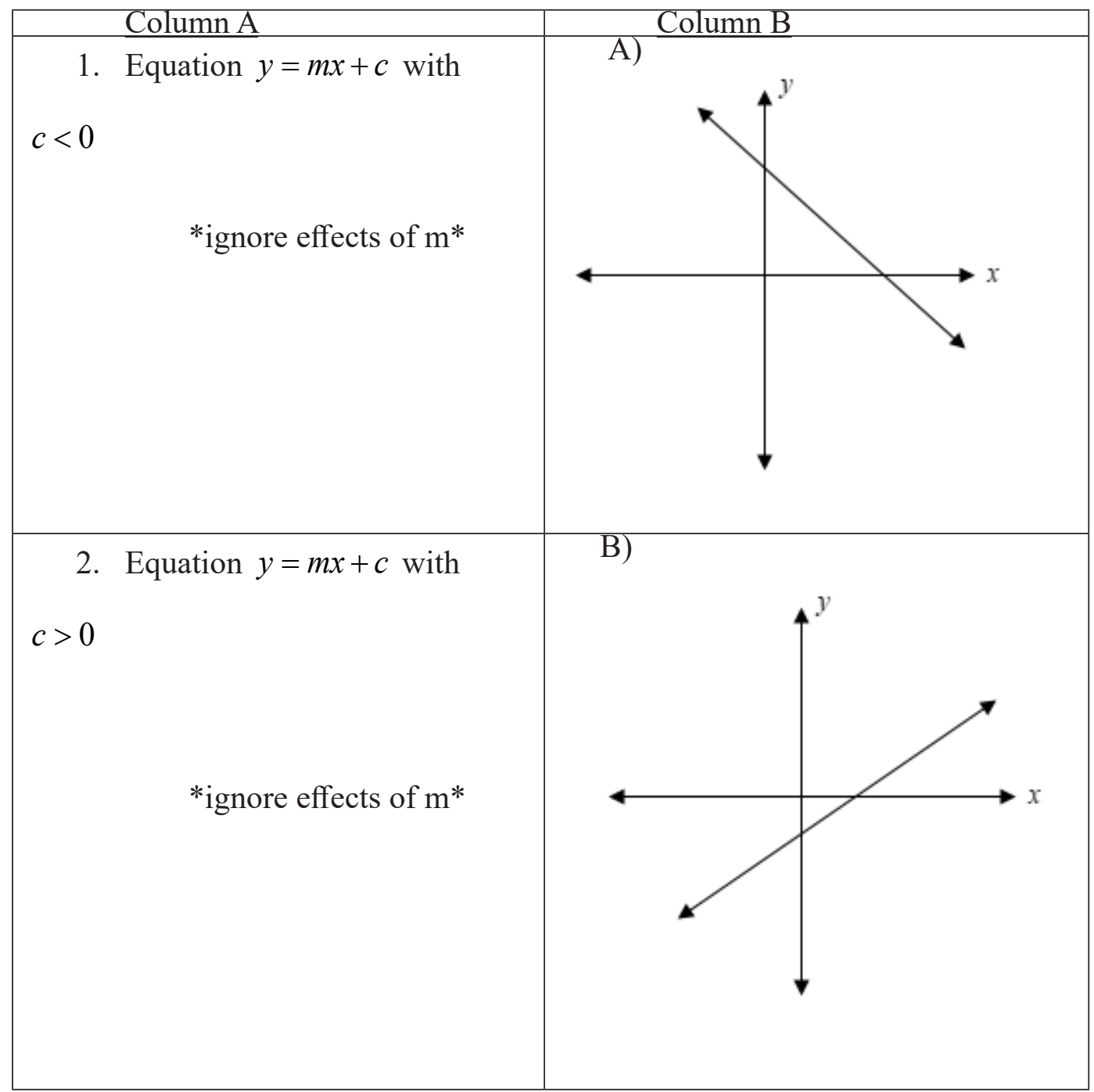

Fill in your answer in the table below:

(Fill in A and B) 


\begin{tabular}{|l|l|l|}
\hline Column A & 1 & 2 \\
\hline Column B & & \\
\hline
\end{tabular}

8. Match the properties described in Column A with the correct (corresponding) graph in Column B.

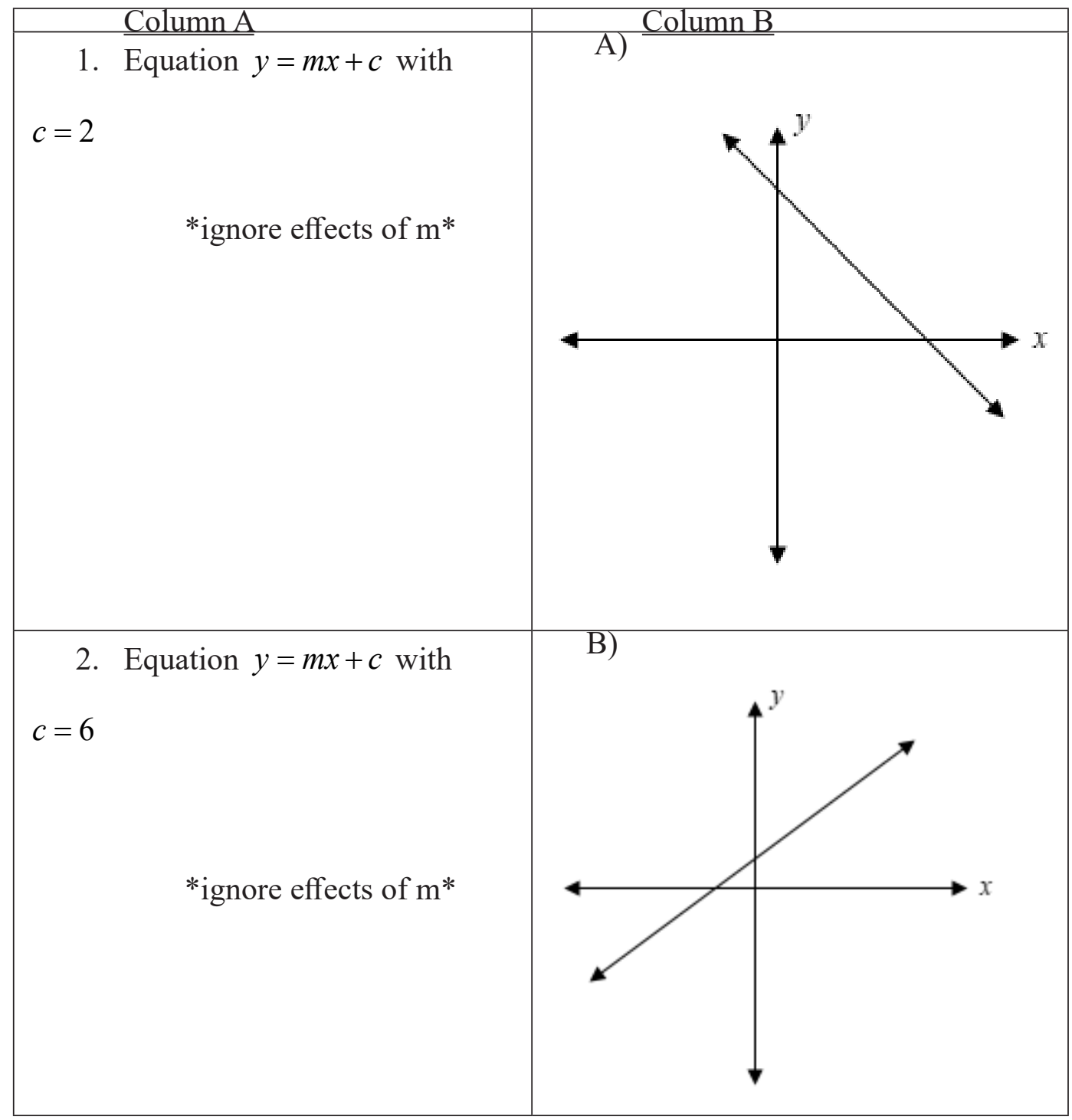

Fill in your answer in the table below:

(Fill in A and B)

\begin{tabular}{|l|l|l|}
\hline Column A & 1 & 2 \\
\hline Column B & & \\
\hline
\end{tabular}


Vimolan MUDALY, Tamryn FLETCHER. The effectiveness of Geogebra when teaching linear functions using the iPad

PROBLEMS

OF EDUCATION

IN THE $21^{\text {st }}$ CENTURY

Vol. 77 , No. 1,2019
(2)

9. Match the properties described in Column A with the correct (corresponding) graph in Column B.

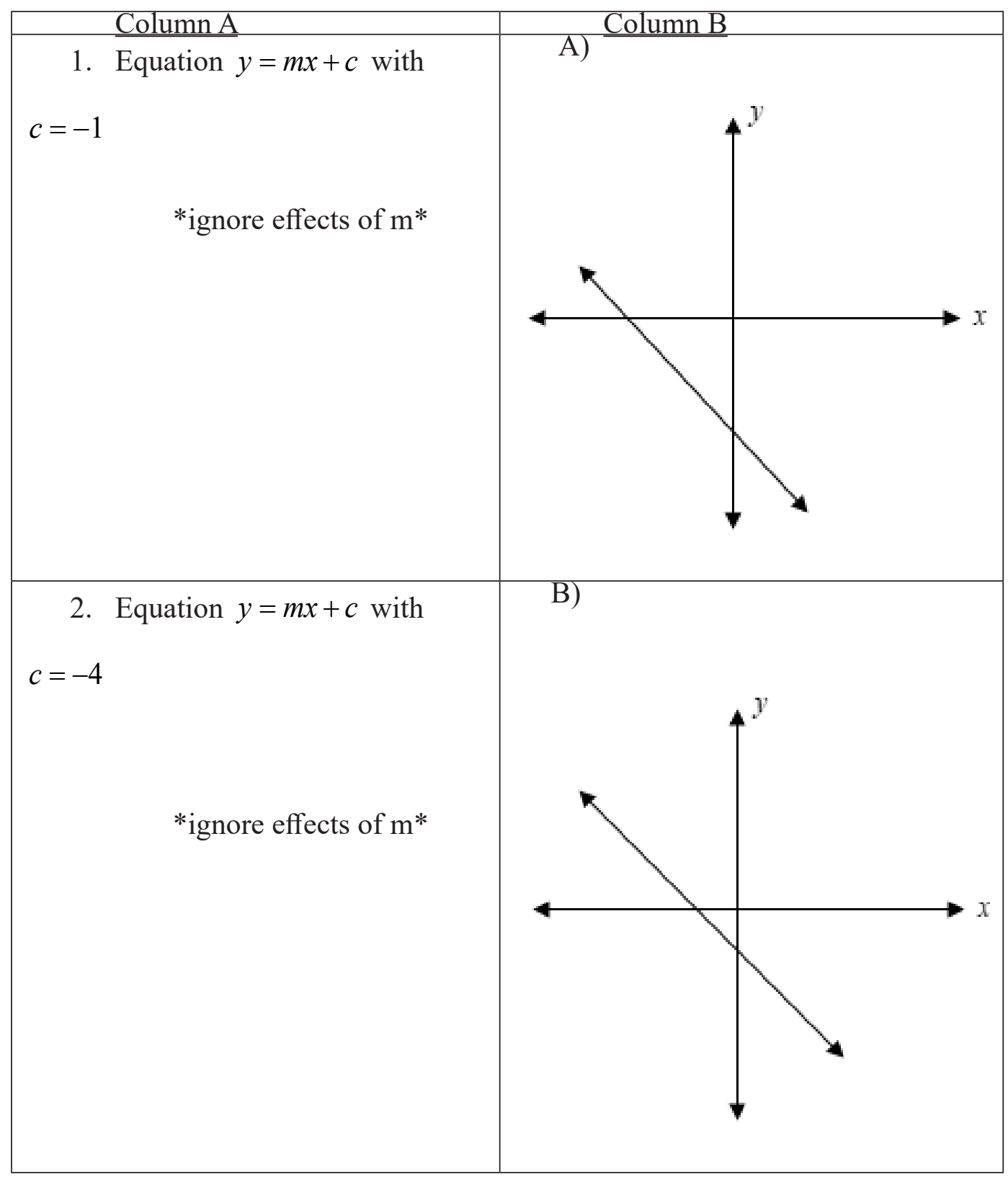

Fill in your answer in the table below:

(Fill in A and B)

\begin{tabular}{|l|l|l|}
\hline Column A & 1 & 2 \\
\hline Column B & & \\
\hline
\end{tabular}

(2) 
10. a) Provide an example of an equation of a straight line graph with $m>0$ and ol. 77 , No. 1,2019 $c<0$

b) Make a rough sketch of the above graph on the axes provided below.

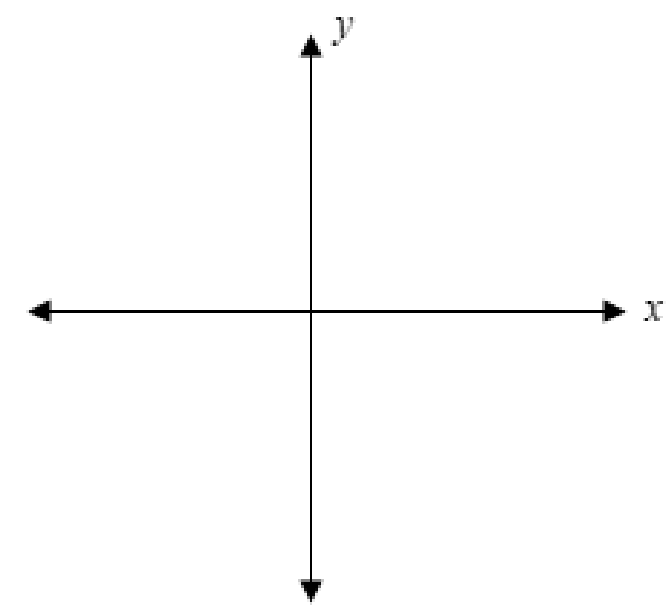

(2)

11. a) Provide an example of a straight line graph with and .

(1)

b) Make a rough sketch of the above graph on the axes provided below. 
Vimolan MUDALY, Tamryn FLETCHER. The effectiveness of Geogebra when teaching linear functions using the iPad

EDUCATION

THE $21^{\text {st }}$ CENTURY

Vol. 77, No. 1, 2019

80

(2)

12. Match the graph in the Cartesian plane with its corresponding equation given in the table.

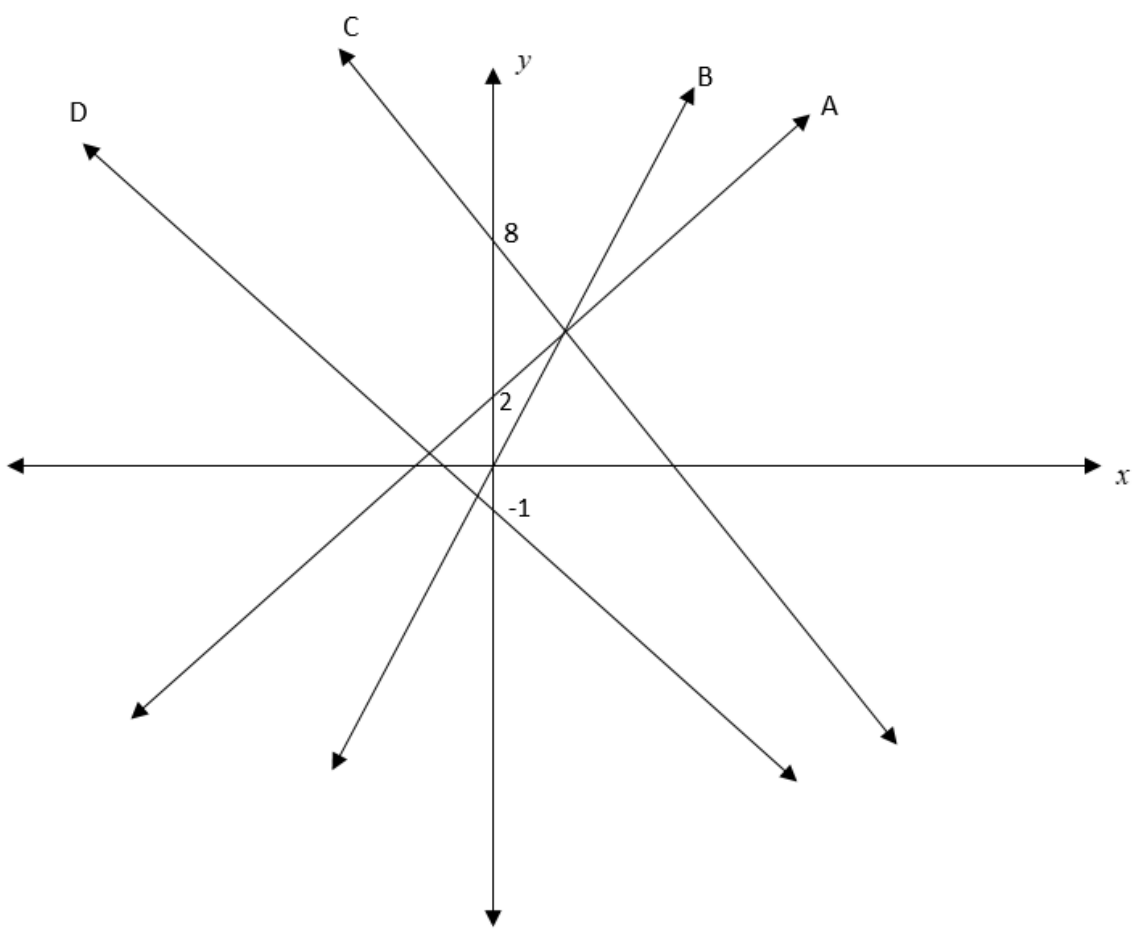

\begin{tabular}{|l|r|}
\hline$\underline{\text { Equation }}$ & Graph \\
\hline$y=-2 x+8$ & \\
\hline$y=x+2$ & \\
\hline
\end{tabular}


Vimolan MUDALY, Tamryn FLETCHER. The effectiveness of Geogebra when teaching linear functions using the iPad

PROBLEMS

OF EDUCATION

IN THE $21^{\text {st }}$ CENTURY

Vol. 77, No. 1, 2019

$y=4 x$

$y=-x-1$

81

(4)

Received: November 19, 2018

Accepted: January 16, 2019

Vimolan Mudaly

PhD, Associate Professor, University of KwaZulu-Natal, 67 Harinagar Drive, Shallcross, Durban, South Africa.

E-mail: mudalyv@ukzn.ac.za

Tamryn Fletcher

Student, University of KwaZulu-Natal, Private Bag X54001, Durban, 4000 South Africa.

E-mail: tamfletch.1@gmail.com 